\title{
Impetus to Innovate Convergence and Library Trends
}

\author{
A. J. Million and Heather Lea Moulaison
}

$\mathrm{T}$

he American Library Association (ALA) lists eleven core values of librarianship: learning, intellectual freedom, preservation, the public good, professionalism, service, and social responsibility. ${ }^{1}$ In keeping with these values, especially the value of access, libraries historically prefer open-access solutions. In an industry white paper from 2013 surveying North American and European librarians on the topic of free online resources and access, the importance of open access was a predominant theme throughout. ${ }^{2}$ Within this environment, information professionals seek high-quality content that will satisfy user needs. Yet, in the future, what trends will influence the use of technology in libraries? How will users expect to access content, and what will that content look like?

In this chapter, we look at library users for indicators of their current and future information-seeking behavior and their information-consumption patterns. We also consider the role of library acquisitions in light of the increasing importance of content as opposed to its carrier. In the following section, we examine and define the concepts of convergence and technological convergence, and what they mean to libraries in light of an emphasis on content and an increasing reliance on technology. Finally, we investigate how convergence is important to libraries now and how it will remain so in the future. 


\section{EVOLVING INFORMATION-SEEKING PARADIGMS}

The needs and information-seeking practices of library patrons are presently evolving. Although power users of library systems will likely always be interested in the most powerful search options available, ${ }^{3}$ not all information seekers require specific sources in order to meet their information needs. Users of information systems, including web users, often satisfice, the "information competency whereby individuals assess how much information is good enough to satisfy their information need." "Good enough" represents a new paradigm in information seeking and requires information providers such as libraries to rethink the content they provide within the context of their stated values.

The amount of information available may not be the only negotiable aspect of information seeking given the information glut that Prabha et al. describe. ${ }^{5}$ Particulars about the carrier, which we define as a content platform, may be less important than the access to the content itself. An e-book may be easier to browse for information on a device than a paper book, but a paper book will suffice in many instances. Blogs may contain content that is equally instructive, and Twitter may alert users to free online resources that further assist them in satisfying their information needs.

Differing carriers serve a purpose, but their content may well be complementary, cumulative, or potentially even interchangeable. In keeping with ALA's Core Values of Librarianship, by providing access to content, libraries may carry out their mission in today's complex information-rich environment. What can be called a format-agnostic focus on content is directly related to the concept of convergence, which may be briefly described as "the flow of content across multiple media platforms," and it is the primary direction in which the library of the future is moving. ${ }^{6}$ Convergence will be discussed in greater detail in the next section.

\section{One-Stop Shopping}

In conjunction with the stated move toward carrier convergence, online shopping habits lend further insight into future user behaviors. Trends in online shopping seem to confirm that Web users are interested in one-stop shopping, the ability to learn one interface and to use it for multiple tasks. Amazon, the iTunes Store, Hulu, and Netflix all represent this model. Amazon has evolved since its inception to allow for the purchase not only of physical books and music, but also of groceries, electronics, and items that are difficult to find locally. The iTunes Store, 
Hulu, and Netflix all offer electronic content in the form of music, movies, games, and television programs. Due to the nature of electronic media and sales, each of these online retailers can stock the widest range possible of content. There is truly something for everyone, as Chris Anderson describes in The Long Tail. ${ }^{7}$

As an example of the notion of something for everyone, we can point to heavy metal as a musical genre. Although brick-and-mortar stores might have a few selections in this category, online music retailers who only need to store the bits and bytes of an MP3 will likely have heavy metal, along with black metal, death metal, blackened death metal, brutal death metal, slam death metal, Swedish death metal (Swedeath), and sludge metal. Given the number of online customers, there will always be someone who will purchase songs in these categories despite their obscurity. The one-stop-shopping phenomenon has come to dominate the business models for online retailers of physical merchandise (e.g. Amazon), allowing for enormous stock, high turnover, and subsequently lower consumer prices.

To simplify their search experience, users often turn to one-stop shopping and prefer access to large collections. The discovery paradigm (dependent on relevance ranking) used in libraries presumes that library users also want a Google-like search box. With many formats and preferences in existence, the desire for simplicity and a universal collection is very strong; enough so, in fact, that one-stop shopping can also extend to physical service points (e.g., a circulation desk that functions as an information desk and assists with reference services). ${ }^{8}$ Everything considered, the implication is that while patrons have carrier and content preferences, they ultimately put a premium on overall convenience. Large collections and effective search tools are one way of offering this.

\section{Library Acquisitions}

Libraries have sought to meet the expectations of patrons for years and will continue to do so well into the future. Presuming that a demand for the "Amazon" one-stop-shopping model extends to libraries, it remains to be seen how and if they can rise to the challenge; especially as adopting it requires the development of large collections of multiformat, digital material. Is a DVD copy of Gone with the Wind enough for users to satisfice, or should a library offer it on Blu-ray as well? If a library's music collection is small and on cassette tape, then will patrons abandon it and rely on commercial outlets and/or competitors instead?

Although the issue has yet to be resolved, a patron-driven acquisition (and thus access) model represents one way for libraries to carry out their missions. For 
electronic content, this approach has been remarked to be "a concept that easily and naturally moves beyond the print and media arenas into electronic books." ${ }^{\prime \prime}$ The point of interest here is not any particular technology or even recent investigations into the patron-driven acquisition model. Instead, given "shifts in the protocols by which we are producing and consuming media," patron-driven acquisitions offers a way for libraries to concurrently satisfice while asking users to select content in the format they prefer. ${ }^{10}$ As media converges in the digital realm and can be used across multiple platforms, patrons expect access to comprehensive collections of material in their preferred format. Although many libraries cannot build onestop-shopping repositories of a magnitude equal to Amazon, what matters is that libraries can still meet user expectations.

We have seen that libraries have strong values and well-defined missions that will continue to guide them well into the future. As patrons continue to change their search and information seeking behaviors, libraries will need to continue to meet their needs. Adaptable acquisitions policies are one way that this can happen.

4 Next, we define the primary concept that will affect libraries, their acquisitions, and their approach to technology in the future: convergence.

\section{CONVERGENCE TECHNOLOGIES}

The general concept of convergence is identified by Jenkins in his book, Convergence Culture. In it, he states that

ideas referenced by the term include the flow of content across multiple media platforms, the cooperation between multiple media industries, the search for new structures of media financing that fall at the interstices between old and new media, and the migratory behavior of media audiences who would go almost anywhere in search of the kind of entertainment experiences they want. ${ }^{11}$

Perhaps the most exciting aspect of a convergence culture is the use of technology to create, share, and access content that could not have otherwise existed. Convergence culture is notably participatory. For example, Jenkins explores the role of technology in the creation and dissemination of Harry Potter fan fiction among the community of young readers. Fan fiction is a kind of "grassroots creative expression" that flourishes when a variety of media and technologies are combined 
by members of a convergence culture to read, celebrate, compose, share, and consume. ${ }^{12}$

Applied to libraries and used by patrons, convergence technologies relate specifically to the multiplicity of platforms and formats (carriers) that can provide content. In the age of information overload, members of Jenkin's convergence culture (e.g., library patrons) cherry-pick content, satisficing as necessary and using one-stop-shopping strategies that are able to meet their information needs. Often, the use of technology plays a leading role in their practices as well. Continuing further, the definition of "convergence technologies" in Technologies of Freedom is those technologies that blur:

the lines between media, even between point-to-point communications, such as the post, telephone and telegraph, and mass communication, such as the press, radio, and television. ${ }^{13}$

In regards to libraries, we identify convergence as the coming together of analog and digital formats in the form of 1 s and Os on digital computers, which may be transmitted electronically online, on air, or by any other form of communication. However, far from being a purely technology-driven phenomenon, the process of convergence also influences culture and patron behavior as well. Since this is the case, the terms convergence and convergence technologies can be used to not only describe digitization but also its cultural impact.

In the realm of convergence culture, technology is nonetheless a means to an end. The definition of technology is a broad and inclusive one, going beyond the notion of new and emerging technologies to embrace any human-made instrument used, in this case, for communication. Technology for technology's sake is never a winning strategy, as technology is simply an instrument to support use. Use, ultimately, is the aspect of activity that matters. Fan fiction is the quintessential creative outlet for some, but others in search of a creative outlet may equally wish to make a video, attend a book club session, or participate in community theater. The need is not for the technology per se, but for the outlet. Libraries have a tradition and a mission of providing both, and in the future, they may see their work converge just as technologies are converging at present. 


\section{CONVERGENCE TECHNOLOGIES IN LIBRARIES}

Given their ubiquity, convergence technologies have found their way into libraries through the many materials that libraries collect and maintain and the events that they host. One obvious instance of convergence is the acquisition of analog media and digital media: format-agnostic patrons may not be concerned about checking out a print book instead of an e-book, or vice versa. MP4 in lieu of a DVD might be just fine for many.

Other issues of convergence might be less obvious. Does an online community bulletin board have the exact same function as the physical one? What about virtual reference books as compared to physical ones? Other questions of convergence strike more closely to the mission of the library. For example, do social tags left by patrons in LibraryThing count as an electronic version of what normally is professional reader's advisory if the patron ends up discovering a book she enjoys?

The question of obsolete technologies also plays a part. Patrons who can appreciate equally a vinyl record, an eight-track tape, a cassette tape, a CD, and an MP3 audio file are probably rare. Film, Betamax, VHS, DVD, Blu-ray, and MP4 video present a similar suite of format options that, though providing identical content, may not be able to meet the information needs of patrons. In the next section, we examine why convergence is the primary concept affecting future library technology trends.

\section{Why Convergence Matters}

The concept of convergence is essential to understanding the way content is consumed, accessed, and used both now and into the future. Thinking about the convergence culture is important to libraries in three ways: the technologies themselves, the systems used, and finally, the content that is offered. In this section, we will examine each in turn and provide insight into the future of convergence in libraries.

\section{Limited Coexistence}

For better or worse, a trend toward convergence sometimes brings competition. This can be problematic, given that the ability of libraries to build collections and provide one-stop-shopping access is often influenced by the unpredictable choices of the technology industry. Although coexistence, openness, and stability would be 
preferable, the reality is that considering the stakes involved with the adoption of shared media standards, cooperation between the giants in the technology sector is frequently undermined by competitive interests seeking to corner the market in their favor.

Several examples are worth noting here, especially Sony's Blu-ray and Toshiba's HD-DVD, as well as Apple's 2010 refusal to support Adobe Flash in its iOS platform. In the case of Blu-ray and HD-DVD, both were launched in 2006. Each sought to become a lucrative industry standard for high-definition optical discs. ${ }^{14}$ Eventually the public adopted Blu-ray, and Sony reaped the benefits-but only after several libraries undoubtedly purchased HD-DVD collections. Steve Jobs's refusal to support Adobe Flash is another case in point; Apple prefers HTML5 as a standard on mobile devices. ${ }^{15}$ Although Flash is not used to build collections of multimedia content, its obsolescence nonetheless indicates a broader trend showing how the interests of nonlibrarians cause some media formats to be adopted by the public while others are not.

Of course, competition extends beyond format standards too; companies and groups have competed to see their hardware or system become an adopted carrier for years. Just as groups often encourage their media format to become the convergent point of market standardization, the same occurs with electronic devices, especially computers. The famous longstanding feud between Apple and Microsoft serves as an example. Microsoft undercut Apple's superior operating system by selling DOS to IBM and the companies who copied IBM's architecture. For Microsoft, this was the serendipitous result of IBM's decision in the early 1980s to adopt open standards. Locked in by its own design, Apple was only able to sell its operating system to a limited number of retailers. The result was that Microsoft's market share grew and Apple's shrank. For the better part of twenty years, few consumers opted to buy anything but a PC.

How can libraries adapt if convergence encourages media companies to compete and create a never-ending stream of digital devices, formats, and standards? Is it possible to avoid turning a digital collection into a metaphorical library of babel? Fortunately, the answer seems to be that there are two solutions. First, competition sometimes results in a better product for both libraries and the public. As Microsoft and Netscape fought to see their respective browsers adopted in the late 1990s, some librarians took the opportunity to evaluate and select what was best for them. ${ }^{16}$ Although competition may incentivize new standards, new products often are better than their predecessors. Second, while competition supercharged by convergence can force libraries to gamble on winners and losers, 
the nature of software, systems, and standards also provides a way forward. In some circumstances, open carrier and content standards represent a competitive advantage that aligns with the library community's preference for openness. Much like the case of Microsoft and IBM's computer standards, the result is that some business models favor stable standards that will not disappear. Libraries will certainly continue to focus on providing access to the content that patrons want and will continue to bet, using their best guesses, on the technology that will be the ones used by patrons according to the missions of their institutions. Open standards, however, ensure that this process is not as risky as it seems.

\section{Library Systems}

Convergence matters not only in the content and technologies that libraries offer, but also in the systems they use to offer files, media, or books. Traditionally libraries have used either vendor-supplied or in-house systems for both their electronic and analog content. With the advent of digital content and media, library technology has adapted, moving online and becoming increasingly sophisticated in the process. Discovery systems now provide seamless access to OPAC and licensed content as well as to locally created content held in institutional repositories and available over the Web.

Libraries have consistently opted to provide or promote creative and open solutions whenever possible. Content creation-including data, resources, metadata, and actual systems- has allowed and will continue to allow libraries to promote openness in providing access. Open-data repositories such as the University of Waterloo's Polar Data Catalogue (www.polardata.ca/whitesnow/) promote the exchange and use of geospatial data about the poles. Resources created by faculty, staff, and students are available in the University of Missouri's MOspace Respository (https://mospace.umsystem.edu) in a format that is OAIPMH harvestable. Metadata about library materials, including "aboutness" and genre tags, can be crowdsourced in integrated library discovery systems, such as BiblioCommons, that supplement library metadata. Finally, libraries promoting the creation of new content though the use of makerspaces, do-it-yourself (DIY) workshops, and other community-involvement initiatives permit the creation of entirely new content in any number of formats to be delivered on any number of platforms or systems.

The continued adherence to open standards, no matter the system or environment, will also continue to serve libraries in the converged future. Linked 
data and the linked open-data movement provide for open standards that permit the use and reuse of data from a number of sources, including libraries. As libraries move to become key players in the linked data web, ${ }^{17}$ their work provides the kind of structure needed for other linked data projects. ${ }^{18}$

Libraries have also promoted creative and open systems-based solutions to satisfy their own technology needs. Technology-centric library platforms have been growing and evolving since the 1960s when MARC (Machine-Readable Cataloging) was created at the Library of Congress. Proprietary and open-source integrated library systems (ILSs) coexist in the broader library ecosystem, and retrospective conversion and the addition of metadata assist with the organization, retrieval, and access to both analog and digital library content. The content of management systems and online, web-based systems complements the analog material housed in libraries. Digital content-licensed from vendors or procured by other meansdoes not replace but instead supplements the library's values of providing access. Drupal, WordPress, Omeka, and others are open-source software suites with robust library-user communities to support library access.

Having embraced convergence technologies by using creative, open solutions, libraries will continue to cultivate a culture of innovation. Specifically, libraries will adopt practical aspects of content management in new systems. This will assist them in carrying out the goal of providing access to library patrons and potentially encourage them to actively flag and/or identify new content for inclusion into a library according to a patron-driven acquisition model. It will also assist them in helping format-agnostic patrons, whose information seeking will continue to be challenged in a dynamic, competitive media environment.

\section{Library Content}

The final aspect of convergence worth discussing is how it impacts the way libraries offer access. After all, in the convergence culture model, the focus is on the mash-up, the creation of new content that could not exist previously. Convergence culture uses technology, but is above all participatory. This participatory component, a somewhat nontraditional approach, is one area in which libraries need to lead the way in providing a safe, reliable, neutral, and supportive environment for members of the convergence culture to go about creating, sharing, and accessing new content. Makerspaces in libraries are an excellent example of libraries promoting the creation of new content. Using a broad definition of technology, other examples may also be identified. Academic libraries that host technology workshops leading 
to the eventual creation of new content or software, public libraries that ask users to comment on novels in the online library catalog, archives that allow for patron interaction with manuscripts-all promote, potentially, a convergence of uses leading to the creation of new content.

One example of a public library planning to promote the creation of new content is the Woodneath Library Center's Story Center, outside of Kansas City, Missouri. The Mid-Continent Public Library's Woodneath Campus will feature:

- Collaboration and program space

- The Woodneath Press, an on-site bookmaking printer

- A digital storytelling technology lab

- A recording booth

- An archive of oral, written, and digital stories produced at the Center ${ }^{19}$

Library patrons will be able to work together collaboratively, much as the Harry Potter fan fiction writers were able to create, record, and share their own content. As content continues to converge across multiple platforms accessible in a variety of systems, libraries will want to be at the fore, offering resources for participating in the convergence culture that is being created.

\section{A CULTURE OF CONVERGENCE}

Library professionals are working in an era unlike any other, and the future promises to be even more exciting. A culture of convergence is driving the way that libraries collect and make information available to their patrons. Information is plentiful, but time and attention are scarce. Strategies that library users adopt in meeting their information needs include satisficing — choosing enough information and information that is good enough-from their preferred one-stop-shopping venue. In this time of technological convergence, libraries continue to be guided by values of providing access to quality content. But the carriers of that content will also change. The importance of access and of the content itself in the library context will persist, regardless of the formats or standards used. The systems that house library content will also continue to change and evolve as patrons' needs and tastes both change and grow. Finally, library content will increasingly reflect the format-agnostic reality of the convergence culture, focusing instead on the content that is relevant and of high quality. 
Librarians must be prepared as we move into the future to continue to offer high-quality resources regardless of the platform or the format. When possible, they will favor open source solutions to meet patron needs. Above all, libraries will position themselves to be the platform that patrons use for the creation of and access to new content and will be a resource in the participatory culture that the convergence culture has enabled.

\section{NOTES}

1. American Library Association, Core Values, Ethics, and Core Competencies, January 27, 2009, www.ala.org/aboutala/governance/policymanual/updatedpolicymanual/ section2/40corevalues.

2. Taylor \& Francis Group, "Facilitating Access to Free Online Resources: Challenges and Opportunities for the Library Community" (white paper), May 2013, www .tandf.co.uk/libsite/pdf/TF-whitepaper-free-resources.pdf.

3. Thomas Mann, "Why LC Subject Headings Are More Important Than Ever," American Libraries 34, no. 9 (October 2003): 52-54; Thomas Mann, "The Changing Nature of the Catalog and Its Integration with Other Discovery Tools, Final Report: March 17, 2006, Prepared for the Library of Congress by Karen Calhoun: A Critical Review," Journal of Library Metadata 8, no. 2 (2008): 169-197, doi:10.1080/10911360802087374; Thomas Mann, "Will Google's Keyword Searching Eliminate the Need for LC Cataloging and Classification?" Journal of Library Metadata 8, no. 2 (2008): 159-168.

4. Chandra Prabha, Lynn Connaway, Lawrence Olszewski, and Lillie Jenkins, "What Is Enough? Satisficing Information Needs." Journal of Documentation 63 (1): 74-89.

5. Ibid.

6. Henry Jenkins, Convergence Culture: Where Old and New Media Collide (New York: New York University Press, 2006), 282.

7. Chris Anderson, The Long Tail: Why the Future of Business Is Selling Less of More (New York: Hyperion, 2008).

8. Janet Crane and Jeanne Pavy, "One-Stop Shopping: Merging Service Points in a University Library," Public Services Quarterly 4, no. 1 (2008): 29-45.

9. Judith Nixon, Robert Freeman, and Suzanne Ward, "Patron-Driven Acquisitions: An Introduction and Literature Review." Collection Management 35, no. 3 (2010): $119-24$.

10. Jenkins, Convergence Culture, 14.

11. Ibid., 282.

12. Ibid., 191. 


\section{Chapter One}

13. Ithil de Sola Pool, Technologies of Freedom (Cambridge, MA: Harvard University Press, 1983), 23, as cited in Jenkins, Convergence Culture, 10.

14. Will Smale, "How the PS3 Led Blu-ray's Triumph," BBC News, February 19, 2008, http://news.bbc.co.uk/2/hi/business/7252506.stm.

15. Steve Jobs, "Thoughts on Flash," Hot News (blog), April 2010, www.apple.com/ hotnews/thoughts-on-flash.

16. Robb Waltner and Everett Algood, "Netscape vs. Internet Explorer," The Serials Librarian 36, nos. 1-2 (1999): 41.

17. For example, the Out of the Trenches project, www.canadiana.ca/en/pcdhn-lod.

18. See the work being undertaken at the Stanford Linked Data Project, http://lib .stanford.edu/stanford-linked-data-project/stanford-linked-data-project-0.

19. "The Future of Woodneath," Mid-Continent Public Library, accessed December 2013, www.mymcpl.org/woodneathplan. 